Bogdan KREMPA

(Stalowa Wola, WZNoS KUL)

\title{
LA VOCATION À LA PRÊTRISE EST-ELLE TRADITIONNELLE?
}

La vocation au presbytérat est souvent présentée comme le choix personnel d'un sujet. En Pologne ou ailleurs l'accent est mis sur le moment de la «rencontre» spirituelle avec Jésus qui dit à son disciple: «Suis-moi» en oubliant parfois que le Seigneur appelle les ministres dans et à travers son Église. Il faut se rendre compte que le désir personnel seul ne suffit pas, que seul est requis le consentement exprimé devant l'Église. C'est la communauté, guidée par l'Esprit Saint, qui choisit un homme, témoigne de lui, prie pour lui et le reçoit. Il y a beaucoup de personnes qui sont responsables de la formation des séminaristes, qui sont attentives à leur vocation. Le premier responsable pour les vocations et l'éducation des «prêtres de demain», est l'évêque diocésain, assisté des professeurs, du séminaire et de la communauté paroissiale à laquelle appartient le candidat. L'éducation complète des élèves des grands séminaires doit tendre à faire d'eux de véritables pasteurs d'âmes, à l'exemple de Notre Seigneur Jésus Christ, Maître, Prêtre et Pasteur ${ }^{1}$.

Dans cet article, nous voudrions essayer de répondre aux questions suivantes : est-ce que la signification actuelle de la vocation au presbytérat, vocation fondée sur le fait de susciter le désir de devenir prêtre est traditionnelle? Qu'est-ce que la tradition peut nous apprendre dans ce domaine? Le sujet touche à l'expérience la plus intime entre Dieu et l'homme, une expérience chaque fois différente, qui est liée à la spiritualité et aussi à la psychologie humaine ${ }^{2}$. Il nous semble que l'on peut y répondre en évoquant les étapes suivants: 1. la tradition biblique sur la vocation, 2. la Tradition de l'Église, 3. la manière dont elles sont vécues dans la situation actuelle.

1. La tradition biblique. On ne peut pas aborder la théologie sans être bien enracinée dans l'Écriture, la source de la pensée chrétienne. Dans l'Écriture

\footnotetext{
${ }^{1}$ Cfr. Concilii Vaticani II Decretum de institutione sacerdotali « Optatam totius » 4-5.

2 Cfr. A. Godin, Psychologie de la vocation. Un bilan, Paris, 1975, 47.
} 
nous avons des exemples de différentes vocations: de la vocation collective ou de la vocation individuelle.

Dans l'Ancien Testament la vocation d'Israël est un acte souverain de la part de Dieu. Dieu choisit librement un peuple parmi les autres pour en faire son peuple. C'est un choix effectué par amour. Par le choix de Dieu, Isral devient sa propriété. Cet appel est ordonné à la mission d'Isral dans le monde. Dieu déclare: «Vous êtes mes témoins» (Is 43, 10). Isral est donc appelé à proclamer, parmi les nations païennes, le Dieu unique et véritable, sur le fondement de la révélation que ce dernier fait de lui-même. Nous pouvons dire la même chose de la vocation individuelle dans la scène de l'appel de Moïse lors de la théophanie du buisson ardent $(\operatorname{Ex} 3,4)$ et de l'appel de Samuel. C'est Dieu qui prend l'initiative. Abraham (Gn 12, 1-3), Moïse (Ex 3, 4), David (1 Sam 16, 1-13) en sont aussi l'illustration. La mission et la responsabilité de l'appelé ne sont pas tributaires de ses talents personnels, mais elles dépendent d'une force qui ne vient pas de l'homme. D'autre part, il n'y a pas de vocation sans mission. Toutes les vocations particulières de l'Ancien Testament sont porteuses de la vocation de tout Israël; c'est la vocation de tout le peuple qui implique des vocations particulières.

Dans le Nouveau Testament la source de l'appel est également Dieu par l'intermédiaire du Christ. La grâce, le dessein et l'amour de Dieu jouent un rôle principal dans cet appel. L'appel vient d'en haut, il est «saint» parce qu'il procède du Dieu saint. Jésus, le Fils de Dieu, a l'initiative d'appeler les personnes à rejoindre le groupe. Les Évangiles rapportent plusieurs cas qui permettent d'entrevoir la situation de ces hommes alors que Jésus accomplissait sa mission parmi son peuple. Arrachés à leur métier, à leur domicile, à leur famille, ils ont vécu avec Jésus, collaborant sur son ordre à sa proclamation du Règne de Dieu.

Le but de l'appel n'est pas la sanctification personnelle de l'appelé, mais il est indiqué par l'appelation de pêcheurs d'hommes que Jésus choisit pour ses disciples. C'est d'abord l'initiative de Jésus qui appelle ceux que lui-même voulait, parmi lesquels il constitue les groupe de Douze (Lc 9, 1; Mt 10, 5; Mc 6,7$)^{3}$. Ce groupe doit être avec lui (Mc 3, 14), non pour mener une existence paisible à ses côtés, mais pour L'accompagner dans ses dplacements et collaborer à son oeuvre.

2. La Tradition de l'Église. D'après la tradition la plus ancienne ${ }^{4}$ le peuple (la communauté), guidée par l'Esprit Saint, choisit un homme, témoigne pour

${ }^{3}$ Cfr. M. Maurice - F. Morel, Dictionnaire grec-français du Nouveau Testament. 4 e édition, Paris 1984, 49-50 ; Grecko-polski Nowy Testament (wydanie interlinearne z kodami gramatycznymi), trad. R. Popowski - M. Wojciechowski, Warszawa 1997.

${ }^{4}$ Cfr. Hippolytus, Traditio Apostolica 2, SCh 11bis, 41: «que soit ordonné comme évêque celui qui a été élu par tout le peuple». 
lui, prie pour lui et le reçoit. Il y a des Pères de l'Église qui ont été élus prêtres ou évêques (p. ex. Ambroise de Milan ou Augustin) de façon inattendue par la volonté du peuple (membres de l'Église). Le désir de l'Église d'avoir tel évêque a été respecté ${ }^{5}$. Il n'a pas de vocation au ministère pastoral en dehors de l'Église. Les vrais critères de la vocation sont toujours les besoins de l'Église au service de l'Évangile, les aptitudes d'un sujet, l'appel de l'Église et le consentement. Toute vocation suppose un appel de Dieu et un geste de l'Église. L'appel de Dieu ne s'objective qu'en devenant un geste d'Église. Dieu appelle l'homme, mais son intervention se réalise toujours à travers des «méditations humaines». Dans chaque cas de vocation à la prêtrise, la tension entre l'action de Dieu, le consentement de l'homme et l'intervention de l' Église est vécue de manière différente, mais on la retrouve toujours.

Dès le milieu du $\mathrm{II}^{\mathrm{e}}$ siècle les ministères chrétiens principaux constituent une trilogie ferme : évêque, prêtre, diacre. Dès le IIIe siècle, sans controverse, les évêques sont désignés comme sacerdotes sous l'influence d'une typologie vétéro-testamentaire plus qu'en relation avec le sacerdoce du Christ. Au IVe siècle, en même mesure en Orient comme en Occident, sera le même vocabulaire utilisé par rapport aux prêtres, mais plutôt moins courramment. Une sacralité de méditation ontologique s'attachera au sacerdoce ordonné bien plus tard, en partie sous l'influence des deux Hiérarchies de Pseudo-Denys ${ }^{6}$. Il faut souligner que les trois grands mouvements réformateurs occidentaux (carolingien, grégorien, tridentin) comprendront toujours plus le sacerdoce ordonné en fonction du sacrifice eucharistique.

En 1912 chanoine Joseph Lahitton a souligné la priorité du rôle de la hiérarchie dans l'appel au sacerdoce. Il absolutisait en quelque sorte la formule du Catéchisme Romain: «Vocari autem a Dio dicuntur qui a legitimis Ecclesiae ministris vocantur» ${ }^{7}$. Pour lui, c'est l'appel de l'Église exprimé par l'appel de l'évêque, qui dépose dans l'âme de l'élu la vocation divine à la prêtrise. La vocation vient de Dieu par l'intermédiaire de l'évêque. Selon lui c'est l'évêque qui appelle au nom de Dieu. Avant le choix de l'évêque, il n'y a pas d'appel de Dieu à chercher en ce domaine. Lahitton a soulevé un débat auquel on a cherché une réponse adéquate. L. Branchereau privilégie les signes personnels et subjectifs de la vocation divine. Il souligne que l'appel de l'évêque est secondaire et «la reconnaissance par l'Église 'appartenant' de fait, en dernier ressort, appartient au directeur spirituel, lequel a reçu de Dieu l'autorité nécessaire pour être interprète de la volonté divine sur la direction de la vie» ${ }^{8}$.

${ }^{5}$ Cfr. H. Legrand, La théologie de la vocation aux ministères ordonnés: vocation ou appel?, „La Vie Spirituelle” 729 (1998) n. 729, 627.

${ }^{6}$ Cfr. Ps.-Dionysius, Hierarchia coelestis, PG 3, 120-369 ; éd. M. de Gandillac, SCh 58, Paris 1958; Hierarchia ecclesiastica, PG 3, 369-584.

${ }^{7}$ Legrand, La théologie de la vocation, p. 627.

${ }^{8}$ L. Branchereau, De la vocation sacerdotale, Paris 1896, 268. 
Pour examiner la question en débat, le pape Pie X constitua une commission cardinalice spéciale qui déclara que l'ouvrage de Lahitton non seulement «n'était nullement à réprouver», mais qu'il était "particulièrement digne d'éloge»" ${ }^{9}$.

Quelques années plus tard, le pape Pie XII, dans son exhortation apostolique sur le sacerdoce Menti nostrae ${ }^{10}$, a expliqué les signes de la vocation, qui étant inscrits dans la personne de l'appelé, le conduisent à s'offrir librement à l'appel de l'évêque. Il a mis l'accent sur les aptitudes, les dons, les capacités en un mot sur l'idonéité de l'appelé. En 1956 le même pape a constaté que l'appel de Dieu et l'appel de l'Église sont «étroitement liés». La formulation du pape veut faire droit à ce qu'elle reconnaît de juste dans les positions présentées ci-dessus par Lahitton et Branchereau. Le texte de Sedes sapientiae insiste sur l'importance de l'élément divin dans la vocation sacerdotale ou religieuse: «s'il fait défaut, on doit dire que le fondement même sur lequel tout l'édifice repose fait aussi défaut ${ }^{11}$. Le texte de Pie XII touche à la question des signes de l'appel de Dieu inscrits dans la personne de l'appelé. Le pape en parlant de dons et de grâce venus de Dieu, il y implique l'intention droite et un certain attrait. Ces termes sont devenus classiques qui, perceptibles dans le psychisme et l'histoire d'un individu, garantissant sinon la certitude absolue, du moins la vraisemblance et la grande probabilité de son «appel par Dieu».

Y. Congar souligne fortement que chaque communauté a le droit de se procurer les prêtres dont elle a besoin. Leur ordination est la conséquence et le signe du caractère pratique du ministère sacerdotal ou hiérarchique, car la prêtrise peut être interprétée comme députation à une fonction publique dans un corps tout entier sacerdotal, le corps de l'Église animé par l'Esprit qui adapte un de ses membres à l'exercice du sacerdoce ${ }^{12}$.

Le Concile Vatican II dans la Constitution dogmatique Lumen Gentium a mis en valeur le fait que, par le baptême, tous les chrétiens sont appelés à la sainteté $^{13}$. La vie spirituelle des pasteurs est enracinée dans le baptême, qui est un appel à la sainteté. La spiritualité des pasteurs ne sera donc pas, en son essence la plus profonde, différente de celle des autres baptisés. Cependant, à cause de la spécifité de leur ministère: présidence à la construction de l'Église, à l'annonce de l'Évangile, à la célébration des sacrements, la spiritualité des pasteurs a un caractère spécifique.

${ }^{9}$ Legrand, La théologie de la vocation, p. 628.

${ }^{10}$ Cfr. Pius XII, Adhortatio Apostolica «Menti Nostrae» (23 IX 1950), AAS 42 (1950) 657-702.

11 Cfr. Pius XII, Constitutio Apostolica «Sedes sapientiae» (31 V 1956), AAS 48 (1956) 354365; M. Sauvage, Vocation, DSp XVI 1092-1158.

12 Cfr. Y. Congar, Les ordinations invitus, coactus, de l'Eglise antique au canon 214, RSPT 50 (1960) 167-197; repris dans: Droit ancien et structures ecclésiales, Londres 1982.

13 Cfr. Concilii Vaticani II Constitutio dogmatica «Lumen gentium» 39. 
Vatican II souligne à plusieurs reprises que la vocation sacerdotale est une vocation au ministère. Le Concile oriente la pastorale des vocations selon la perspective missionnaire. La sensibilisation aux besoins de l'Église et du monde est inséparable de l'éducation à la disponibilité aux appels intérieurs de l'Esprit. L'appelé doit être conscient de la sollicitude du Seigneur pour son troupeau. Si le Seigneur l'appelle, il doit être prêt à répondre généreusement avec le prophète: «Me voici, envoie-moi» (Is 6, 8).

3. La situation contemporaine. La vocation est l'expérience d'un Dieu qui parle à un homme qui écoute, d'un Dieu qui élit gratuitement un homme libre qui y consent, d'un Dieu qui fait alliance avec un homme, lequel adhère à cette alliance et envisage de devenir collaborateur de Dieu dans son action au salut du monde. Le Dieu chrétien est un Dieu qui parle, et si ses appelés deviennent des prophètes, des hommes de la parole, c'est d'abord pour avoir accueilli la «parole de Dieu» comme interpellation dans leur vie. Dieu qui appelle intervient dans l'histoire avec sa parole créatrice, il introduit un changement dans l'histoire de l'homme appelé. Cette parole de Dieu en quelque sorte engendre à nouveau à lui-même l'homme appelé.

Mais cet appel personnel de Dieu est inséparable de la vocation provenant du peuple, de l'Église. Ce «lien», on l'apperçoit dans le rite de l'ordination diaconale ou sacerdotale. Ce n'est pas le futur diacre, prêtre ou évêque qui demandent leur ordination, mais c'est l'Église qui est bel et bien le sujet de cette demande: «Père, (dit à l'évêque ou à celui qui tient lieu), la sainte Église vous demande d'ordonner diacre/prêtre un tel...». Selon le canon $1036 \mathrm{du}$ Code de Droit Canonique de 1983, l'ordinand (diacre/prêtre) n'est que le sujet de l'acceptation de l'ordination, mais il doit demander par écrit à son évêque «d'être admis à recevoir cet ordre» ${ }^{14}$.

L'ordination se fait par l'imposition des mains et par la prière épiclétique. Seuls les évêques le font au nom de toute l'Église, et en même temps la communauté présente participe activement par la prière. Il faut souligner en ce lieu que les autres évêques et les prêtres présents expriment par l'imposition des mains sur le nouveau prêtre ordonné la collégialité des ministres. C'est un détail qui prouve le rôle de la communauté ecclésiale dans la vie de l'appelé.

L'appel d'une personne est aussi envoi à ce peuple, et au-delà du peuple, à l'humanité. La personne appelée rencontre l'Église qui offre une diversité de ministère dans différentes formes de vie; ils sont tous au service du Corps Mystique du Christ, au service de l'Église, de ses membres et de sa mission

${ }^{14}$ Cfr. Codex Iuris Canonici (1983) can. 1036 - Pour pouvoir être promu au diaconat ou au presbytérat, le candidat remettra à l'Évêque propre ou au Supérieur majeur compétent une déclaration écrite et signée de sa propre main, par laquelle il atteste qu'il recevra l'ordre sacré spontanément et librement et qu'il se consacrera pour toujours au ministère ecclésiastique, demandant en même temps d'être admis à recevoir l'ordre. 
pour le monde. Être appelé par l'Église à un ministère déterminé, c'est engager dans un dialogue qui doit nourrir la relation personnelle de chacun avec Dieu, et la communion ecclésiale des membres de l'Église. Le service ministériel n'est pas d'intimité authentique avec le Dieu de l'Alliance sans épouser son élan créateur vers le monde. Il est difficile d'imaginer la vie dans le Christ sans partager son dynamisme d'Incarnation et de Rédemption pour le salut du monde et la vie dans l'Esprit, qui conduit au service des hommes. La meilleure école de la mission au service de l'Église pour toutes les formes de vocation particulière c'est l'école du service du Seigneur et la participation au Mystère de Jésus Christ, mystère d'Incarnation, de présence dans le monde et aussi de solidarité.

Au cours de l'histoire, et spécialement durant le dernier siècle, les sociétés ont beaucoup changé, et le statut social de pasteurs dans la société a changé lui aussi. L'évolution des sociétés ne constitue pas seulement un défi, voire une menace pour l'Église, mais il est aussi une chance pour les ministères dans l'Église. On voit la démocratisation des sociétés, le pluralisme, les droits de l'homme, la reconnaissance de l'égalité juridique des femmes, la plus grande qualification culturelle de la population, ce sont-là des ressources qui peuvent aider l' Église à appeler aux ministères, en renouant avec la tradition plus ancienne. Cela se fait en redonnant leur rôle aux Églises locales, aux structures collégiales et synodales. Les formes concrètes de l'exercice du ministère sont aussi un signe pour nos sociétés : l'annonce de la Bonne Nouvelle ne peut être séparé des messagers et de la manière dont les massagers vivent la communion du salut.

En répondant à la question posée au début on peut constater qu'il n'est pas possible de maintenir status quo. Les réalités de notre vie changent très vite, la mentalité des jeunes change, ils rêvent souvent d'une vie facile, d'un métier original, d'études à l'étranger. Tout cela exerce une influence sur le problème de la vocation au presbytérat, qui est bien complexe. En pratique l'accent peut être mis sue les différents points de la tradition. Le vrai critère de la vocation est multiple: désir personnel de devenir prêtre (qui ne décide pas suffisamment de l'authenticité de la vocation), besoin concret de l'Église au service de l'Évangile, aptitudes d'un sujet, appel de l'Ecclesia qui s'occupe également de l'éducation de ses enfants.

Il est clair, malgré tout, que l'Église a besoin de nouveaux ministères et que Jésus appelle sans sesse des hommes au service sacerdotal. On observe dans le monde une tendance à la diminution des vocations. L'Église souffrante dans les pays de l'Europe-Est donne de nouveaux prêtres qui continuent l'oeuvre de Dieu pour le salut des hommes. Ce sont des événements qui se passent sous nos yeux, dans la vie quotidienne. Les vocations sont toujours l'initiative de Dieu qui est présent et qui agit aux coeurs de ses fidèles.

Sans aucun doute la signification actuelle de la vocation puise les modèles dans la tradition, en envisageant les besoins de l'Église, de la communauté et 
l'invitation de Jésus lui-même qui révèle petit-à-petit sa pédagogie. Dans le processus de reconnaissance de la vocation au presbytérat, le désir de devenir prêtre est important, mais il n'est pas la mesure définitive. Il faut tenir d'autres éléments: la réponse à l'appel divin, le consentement du sujet, la consécration de la vie au service de Dieu et au salut du monde, autant d'éléments qui sont exprimés pendant la liturgie de l'ordination sacerdotale.

\title{
CZY POWOEANIE DO KAPŁAŃSTWA JEST TRADYCYJNE?
}

\author{
(Streszczenie)
}

Artykuł zawiera trzy zasadnicze punkty, które stanowią próbę odpowiedzi na następujące pytania: czy powołanie zbudowane tylko na pragnieniu pozostania księdzem jest tradycyjne? W jaki sposób Kościół jako wspólnota ludzi wierzących edukuje swoich powołanych? Co Tradycja może nas nauczyć w tym względzie?

1. Tradycja biblijna ukazuje nam przykłady różnych powołań: indywidualnych i kolektywnych. W Starym Testamencie powołanie Izraela było suwerennym aktem ze strony Boga, który zwracał się także po imieniu do wybranych mężczyzn. Misja i odpowiedzialność powołanego nie zależały od jego talentów, lecz od siły mającej swe źródło w Bogu. W Nowym Testamencie źródłem powołania jest również Bóg, ale przez pośrednictwo Jezusa. Łaska, zamysł i miłość Boża odgrywały zasadniczą rolę w powołaniu.

2. Tradycja Kościoła wskazuje na głos ludu w powoływaniu kapłanów lub biskupów, jak to miało miejsce w przypadku Ambrożego czy Augustyna. Nie ma powołań do służby kapłańskiej poza Kościołem. Pragnienie Kościoła wyboru mężczyzn na kapłanów czy biskupów zostało zrealizowane a prawdziwymi kryteriami powołania są potrzeby wspólnoty w służbie Ewangelii, zdolności powołanego, wezwanie Kościoła i zgoda zainteresowanego. W 1912 roku spór Branchereau - Lahitton przyczynił się do potwierdzenia przez papieża Piusa X tradycyjnej doktryny na temat powołania jako wezwania Boga, realizowanego we wspólnocie Kościoła.

3. Współczesna sytuacja. Powołanie jest doświadczeniem Boga, który przemawia do mężczyzny, który Go słucha. Wezwanie skierowane do konkretnej osoby jest nierozdzielne z powołaniem pochodzącym od ludu (od Kościoła). Ten związek jest obecny w rycie święceń diakonatu czy prezbiteratu: „Święta Matka Kościół prosi...”. Święcony wyraża w tym czasie swoją zgodę. Wezwanie jest równocześnie posłaniem do tego ludu, z którego wywodzi się kandydat do święceń. Można stwierdzić, że powołanie jest procesem wychowawczym całego Kościoła na różnych etapach jego zrodzenia, wzrostu i weryfikacji. Stąd też do święceń wymaga się odpowiednich opinii o kandydacie, wyrażonych przez głos ludu z którego on pochodzi. 